CLINICAL STUDY

\title{
The effects of endothelial nitric oxide synthase gene polymorphisms on endothelial function and metabolic risk factors in healthy subjects: the significance of plasma adiponectin levels
}

\author{
Akiko Imamura, Ryotaro Takahashi, Ryuichiro Murakami, Hiroki Kataoka, Xian Wu Cheng ${ }^{1}$, \\ Yasushi Numaguchi ${ }^{2}$, Toyoaki Murohara and Kenji Okumura ${ }^{1}$ \\ Department of Cardiology, Nagoya University Graduate School of Medicine, Nagoya, Japan, ${ }^{1}$ Cardiovascular Research Medicine, 65 Tsurumai-cho, \\ Showa-ku, Nagoya 466-8550, Japan and ${ }^{2}$ Medical Science of Proteases, Nagoya University School of Medicine, Nagoya, Japan \\ (Correspondence should be addressed to K Okumura; Email: kenji@med.nagoya-u.ac.jp)
}

\begin{abstract}
Objective: Genetic variants of the endothelial nitric oxide synthase (eNOS) gene, Glu298Asp and $\mathrm{T}-786 \mathrm{C}$, have been reported to be associated with cardiovascular disease. Adiponectin is an adipocytederived plasma protein with insulin-sensitizing and vascular protective effects; its levels are typically low in metabolic syndrome. Therefore, eNOS gene polymorphisms may also be associated with specific metabolic profiles, including plasma adiponectin levels and atherogenic lipids.

Methods: We evaluated the functional significance of eNOS gene Glu298Asp and T-786C polymorphisms on endothelial function and metabolic profiles in 101 healthy young men (mean age 30.3 years) before the progression of atherosclerotic lesions.

Results: No linkage disequilibrium was found between the two genotypes. The Asp298 allele carriers of the eNOS gene presented significantly higher plasma low density lipoprotein (LDL) cholesterol, LDL particle size, malondialdehyde-modified LDL (MDA-LDL), and fasting insulin levels and lower plasma high density lipoprotein (HDL) cholesterol, apolipoprotein A-I levels, and endothelium-dependent vasodilation when compared with noncarriers. In spite of higher MDA-LDL levels, Asp298 carriers had significantly larger LDL particle size. By contrast, in C-786 allele carriers, systolic blood pressure was significantly higher, and plasma high-molecular-weight adiponectin levels and endotheliumdependent vasodilation were significantly lower than those in non-carriers. Conclusions: Although both eNOS polymorphisms induced endothelial dysfunction, the eNOS T-786C polymorphism may be associated with adiponectin levels, whereas the Glu298Asp polymorphism may be associated with atherogenic lipid levels.
\end{abstract}

European Journal of Endocrinology 158 189-195

\section{Introduction}

Metabolic syndrome, a cluster of the accumulation of visceral adipose tissue, insulin resistance, hyperglycemia, atherogenic dyslipidemia, and hypertension, has been suggested to contribute to the development of atherosclerosis and cardiovascular disease $(1,2)$. Adiponectin is an adipocyte-derived plasma protein, which has roles in preventing the development of atherosclerosis and the impairment of glucose and lipid metabolisms (3). Adiponectin expression and secretion from white adipose tissue are regulated by various factors including obesity, insulin-resistant status, and also some genetic backgrounds (4-6).

It has been reported that insulin stimulation of glucose uptake in skeletal muscle and adipose tissue in vivo is nitric oxide (NO) dependent in rats $(7,8)$. Other data have indicated that flow-induced dilation in visceral fat arterioles is NO dependent in the absence of known coronary artery disease (9). Recent animal data suggested that endothelial nitric oxide synthase (eNOS) knockout mice presented with a phenotype of insulin resistance, hypertension, and dyslipidemia, resembling that observed in human metabolic syndrome, especially under nutritional stress $(10,11)$.

In humans, several gene polymorphisms of eNOS have been detected; the eNOS G894T (Glu298Asp) and $\mathrm{T}-786 \mathrm{C}$ polymorphisms, in particular, are reported to be related to cardiovascular disease. These eNOS gene polymorphisms have also been associated with insulinresistant state $(12,13)$, type 2 diabetes mellitus (14), higher plasma-oxidized low density lipoprotein (LDL) during acute phase of myocardial infarction (15), and metabolic syndrome (16). However, the effects of eNOS gene polymorphisms on metabolic profiles including plasma adiponectin and atherogenic lipid levels have not 
been fully determined. The aim of the present study was to investigate phenotypic differences including differences in endothelial function and metabolic profile between two polymorphisms of eNOS, Glu298Asp and T-786C, in young healthy men before the expression of atherosclerotic diseases by genetic and environmental contributions.

\section{Subjects and methods}

\section{Study subjects}

We studied 101 young, apparently healthy men (mean age $30.3 \pm 4.2$ years; range $25-39$ years). All subjects were volunteers, had no previous history of diabetes or cardiovascular disease, and received no medication. The study was approved by the Ethics Committee of Nagoya University and written informed consent was obtained from all subjects.

\section{Vascular study}

After overnight fasting, blood pressure was measured and assessment of brachial artery function was performed according to a previously described non-invasive technique (17). Using high-resolution ultrasound cardiography (SONOS 5500, Agilent Technologies Inc., Palo Alto, CA, USA), the end-diastolic diameter of the right brachial artery and blood flow by pulse wave Doppler ultrasound were measured. The diameter of the right brachial artery was measured from the anterior to the posterior interface between the media and adventitia, and the mean of three measurements was calculated.

Measurements of flow-mediated dilation (FMD), an endothelium-dependent response, were taken at baseline, then at 1 min after forearm hyperemia (produced by releasing a forearm cuff inflated to $250 \mathrm{mmHg}$ for $5 \mathrm{~min}$ ), and finally at rest after the subject had been lying quietly for $10 \mathrm{~min}$. Then, after the diameter was recovered to the level of the baseline diameter, glyceryl trinitrate-induced dilation (GTN), an endotheliumindependent dilation, was assessed 3 and 5 min after sublingual application of $300 \mu \mathrm{g}$ glyceryl trinitrate.

Participants were asked to refrain from smoking within $24 \mathrm{~h}$ of the measurement.

\section{Biochemical analyses}

In all subjects, an overnight fasting venous blood sample was obtained on the same day as flow measurements. Standard assays were used to measure serum concentrations of total cholesterol, high density lipoprotein (HDL) cholesterol, LDL cholesterol, and triglycerides as well as insulin, glucose, and HbAlc levels. For estimation of insulin sensitivity, a homeostasis model assessment of insulin resistance (HOMA-IR) was calculated. Plasma total adiponectin and high-molecular-weight (HMW) adiponectin concentrations were measured by sandwich ELISA (Otsuka Pharmaceuticals, Tokyo, Japan and
Fujirebio, Tokyo, Japan respectively) as previously described (18).

\section{Genotyping of the eNOS Glu298Asp and $\mathrm{T}-786 \mathrm{C}$ polymorphisms}

Genomic DNA was prepared from peripheral blood leukocytes using a QIAamp DNA blood minikit (Qiagen). Genotypes for the Glu298Asp and T-786C polymorphisms were determined by PCR-restriction fragment length polymorphism analysis using specific oligonucleotide primers (Glu298Asp: sense, 5'-AAC ACC ACT TTC CTG AGC-3' and anti-sense, 5'-CTT ATC CTG ACA CAT TTT GAG A-3'; T-786C: sense, 5'-CAT TCT GGG AAC TGT-3' and anti-sense, 5'-GTC AGC AGA GAG ACT-3'). PCR products were digested by BanII and MspI for the Glu298Asp and T-786C polymorphisms respectively and were separated by a $2.5 \%$ agarose gel and an $8 \%$ polyacrylamide gel for the Glu298Asp and T-786C polymorphisms respectively.

\section{LDL particle size}

EDTA plasma samples were stored frozen at $-70{ }^{\circ} \mathrm{C}$ until analysis. The LDL particle size was determined by electrophoresis using non-denaturing $4-14 \%$ polyacrylamide gradient gels with modified methods (19). In brief, $7.5 \mu \mathrm{l}$ plasma samples were applied on gels with a final concentration of $20 \%$ sucrose and $0.25 \%$ bromophenol blue. After electrophoresis, the gels were scanned (CS9300; Shimadzu Co., Kyoto, Japan) and migration distances (from the top of the gel to the most prominent band) were measured. The apparent diameters of major LDL particles were measured by comparing results with a calibration curve constructed with ferritin, thyroglobulin, and latex beads. The estimated diameter for the major peak in each scan was identified as the LDL particle size.

\section{Malondialdehyde-LDL (MDA-LDL)}

The ELISA used for measurement of MDA-LDL was based on the method reported by Kotani et al. (20). In brief, microtiter plates were coated with a monoclonal antibody against MDA-LDL. Duplicate $100 \mu$ samples were added to the wells of the plates and incubated. After washing, a $\beta$-galactosidase-conjugated monoclonal antibody against apoB was added to each well. After washing, $100 \mu \mathrm{l}$ substrate solution, $o$-nitrophenyl$\beta$-galactopyranoside $(10 \mathrm{mmol} / \mathrm{l})$, was dispensed into each well and allowed to react. The reaction was terminated by a stop solution, and absorbance was determined spectrophotometrically at $415 \mathrm{~nm}$.

\section{Statistical analysis}

Data are reported as mean \pm s.D. Data were analyzed using the StatView 5.0 software program (SAS 
Institute, Cary, NC, USA). Continuous variables were tested for normal distribution by the KolmogorovSmirnov test. When data were not normally distributed (i.e., triglycerides, fasting insulin, and HOMA-IR), they were logarithmically transformed before statistical analysis. The $\chi^{2}$-test was used for genetic linkage between the two eNOS polymorphisms, and multilocus haplotype frequencies were estimated using the iterative expectation maximization algorithm (21). The unpaired Student's $t$-test was used to calculate the statistical significance between the presence and absence of the Asp296 or $\mathrm{C}-786$ allele. A value of $P<0.05$ was considered statistically significant.

\section{Results}

\section{Baseline characteristics of study participants and genotype frequencies of eNOS polymorphisms}

Table 1 shows the clinical characteristics of study participants. Of the 101 subjects enrolled in the study, 9 had hypertension (systolic blood pressure $\geq 140 \mathrm{mmHg}$ and/or diastolic blood pressure $\geq 90 \mathrm{mmHg}$ ), 8 had hypercholesterolemia (total cholesterol $>6.2 \mathrm{mmol} / \mathrm{l}$ and/or LDL cholesterol $>4.1 \mathrm{mmol} / \mathrm{l}$ ), and $15 \mathrm{had}$ hypertriglycedemia $(>1.7 \mathrm{mmol} / \mathrm{l})$. There was only one subject with hyperinsulinemia $(>240 \mathrm{mmol} / \mathrm{l})$. Sixteen subjects had obesity (body mass index, BMI $>25 \mathrm{~kg} / \mathrm{m}^{2}$ ). Study subjects were relatively young, apparently healthy, and neither took medication nor had ever been diagnosed

Table 1 Clinical characteristics of healthy male subjects.

\begin{tabular}{lc}
\hline Variables & \\
\hline Age (years) & $30.3 \pm 4.2$ \\
BMI (kg/m²) & $22.9 \pm 2.5$ \\
Systolic blood pressure $(\mathrm{mmHg})$ & $121 \pm 12$ \\
Diastolic blood pressure $(\mathrm{mmHg})$ & $71.5 \pm 8.9$ \\
Total cholesterol (mmol/l) & $4.89 \pm 0.78$ \\
HDL cholesterol $(\mathrm{mmol} / \mathrm{l})$ & $1.51 \pm 0.32$ \\
LDL cholesterol $(\mathrm{mmol} / \mathrm{l})$ & $2.97 \pm 0.67$ \\
Triglycerides $(\mathrm{mmol} / \mathrm{l})$ & $1.40 \pm 1.60$ \\
LDL particle size $(\mathrm{nm})$ & $26.6 \pm 0.9$ \\
MDA-LDL $(\mathrm{U} / \mathrm{L})$ & $108 \pm 55$ \\
Apolipoprotein A-I $(\mathrm{mg} / \mathrm{dl})$ & $138 \pm 20$ \\
Apolipoprotein B $(\mathrm{mg} / \mathrm{dl})$ & $83.5 \pm 18.8$ \\
Fasting glucose $(\mathrm{mmol} / \mathrm{l})$ & $5.35 \pm 0.57$ \\
HbA1c $(\%)$ & $4.69 \pm 0.28$ \\
Fasting insulin $(\mathrm{pmol} / \mathrm{l})$ & $64 \pm 50$ \\
HOMA-IR value & $2.68 \pm 2.66$ \\
Total adiponectin $(\mu \mathrm{g} / \mathrm{ml})$ & $7.34 \pm 3.60$ \\
HMW adiponectin $(\mu \mathrm{g} / \mathrm{ml})$ & $3.86 \pm 2.47$ \\
FMD & $4.7 \pm 2.4$ \\
GTN & $16.3 \pm 5.1$ \\
FMD/GTN & $0.30 \pm 0.14$ \\
\hline
\end{tabular}

Values are expressed as mean \pm s.D. BMI, body mass index; MDA-LDL, malondialdehyde-LDL; HOMA-IR, homeostasis model assessment of insulin resistance; HMW, high-molecular-weight; FMD, flow-mediated dilatation; GTN, glyceryl trinitrate-induced dilation.
Table 2 Genotype distribution and association of the eNOS Glu298Asp and T-786C polymorphisms.

\begin{tabular}{lcccr}
\hline \multicolumn{5}{c}{ Glu298Asp } \\
\cline { 2 - 5 } T-786C & $\begin{array}{c}\text { Glu/Glu } \\
(\mathrm{G} / \mathrm{G})\end{array}$ & $\begin{array}{c}\text { Glu/Asp } \\
(\mathrm{G} / \mathrm{T})\end{array}$ & $\begin{array}{c}\text { Asp/Asp } \\
(\mathrm{T} / \mathrm{T})\end{array}$ & Total \\
\hline T/T & 61 & 16 & 4 & 81 \\
T/C & 14 & 5 & 0 & 19 \\
C/C & 1 & 0 & 0 & 1 \\
Total & 76 & 21 & 4 & 101 \\
\hline
\end{tabular}

There was no linkage disequilibrium between the Glu298Asp and T-786C polymorphisms by the expectation maximization algorithm for haplotype inference $\left(\Delta=7 \times 10^{-7}\right)$ and by the $\chi^{2}$-analysis $\left(\chi^{2}=0.007, P=0.93\right)$.

with diabetes or cardiovascular disease. Two subjects had fasting glucose levels above $7.0 \mathrm{mmol} / \mathrm{l}$.

The distributions of the eNOS Glu298Asp and T-786C polymorphisms are shown in Table 2. Genotype and allele frequencies for the two polymorphisms were similar to those described previously in a Japanese population (22). The distributions were compatible with the Hardy-Weinberg equilibrium. Twenty-five percent of subjects were positive for the G894T polymorphism, $20 \%$ for the T-786C polymorphism, and 5\% carried mutated alleles in both loci. There was no linkage disequilibrium between the Glu298Asp and T-786C polymorphisms by the expectation maximization algorithm for haplotype inference $\left(\Delta=7 \times 10^{-7}\right)$ and by the $\chi^{2}$-analysis $\left(\chi^{2}=0.007, P=0.93\right)$.

\section{Effects of the eNOS Glu298Asp and T-786C polymorphisms on vascular study}

Endothelial NO production was assessed by comparing FMD in response to flow with GTN in the brachial artery. Namely, to normalize the changes in FMD for changes due to glyceryl trinitrate instead of comparing the absolute changes in FMD, the ratio of FMD to GTN (FMD/GTN) was calculated (23). Both the Asp298 and the C-786 significantly reduced endothelium-dependent vasodilation by $26 \%(P=0.02)$ and $23 \%(P=0.05)$ respectively, indicating that the alleles inhibit the endothelial function to the same extent (Tables 3 and 4).

\section{Differences in clinical characteristics assigned to eNOS genotypes}

Clinical characteristics were shown in Tables 3 and 4 between two subgroups that are divided according to the presence of Asp298 or C-786 alleles respectively. In the Asp298 carriers, plasma LDL cholesterol $(P=0.04)$, LDL particle size $(P=0.003)$, and MDA-LDL $(P=0.05)$, fasting insulin $(P=0.04)$, and HOMA-IR values $(P=0.04)$ were significantly higher than those in the non-carriers. Plasma HDL cholesterol $(P=0.01)$ and apolipoprotein A-I levels $(P=0.003)$ were significantly 
Table 3 Physical and biochemical characteristics of subjects assigned by the presence of the eNOS Asp298 allele.

\begin{tabular}{|c|c|c|c|}
\hline eNOS Glu298Asp & Glu/Glu $(n=76)$ & Glu/Asp or Asp/Asp $(n=25)$ & $P$ value \\
\hline Age (years) & $30.2 \pm 4.3$ & $30.4 \pm 4.0$ & 0.83 \\
\hline BMI $\left(\mathrm{kg} / \mathrm{m}^{2}\right)$ & $22.6 \pm 2.5$ & $23.7 \pm 2.7$ & 0.062 \\
\hline Systolic blood pressure (mmHg) & $122 \pm 13$ & $119 \pm 9$ & 0.22 \\
\hline Diastolic blood pressure $(\mathrm{mmHg})$ & $71.1 \pm 9.4$ & $72.8 \pm 7.1$ & 0.42 \\
\hline Total cholesterol $(\mathrm{mmol} / \mathrm{l})$ & $4.85 \pm 0.74$ & $4.97 \pm 0.86$ & 0.52 \\
\hline HDL cholesterol (mmol/l) & $1.56 \pm 0.33$ & $1.37 \pm 0.26$ & 0.011 \\
\hline LDL cholesterol (mmol/l) & $2.88 \pm 0.60$ & $3.20 \pm 0.84$ & 0.035 \\
\hline Triglycerides $(\mathrm{mmol} / \mathrm{l})$ & $1.43 \pm 1.78$ & $1.37 \pm 0.83$ & 0.48 \\
\hline LDL particle size (nm) & $261.2 \pm 9.8$ & $268.0 \pm 8.5$ & 0.003 \\
\hline MDA-LDL (U/L) & $102.5 \pm 53.9$ & $122.2 \pm 45.5$ & 0.046 \\
\hline Apolipoprotein A-I (mg/dl) & $141.3 \pm 19.5$ & $127.8 \pm 18.1$ & 0.003 \\
\hline Apolipoprotein B (mg/dl) & $81.7 \pm 17.4$ & $88.3 \pm 22.1$ & 0.13 \\
\hline Fasting glucose (mmol/li) & $5.31 \pm 0.51$ & $5.46 \pm 0.71$ & 0.25 \\
\hline $\mathrm{HbA1c}(\%)$ & $4.67 \pm 0.29$ & $4.77 \pm 0.26$ & 0.11 \\
\hline Fasting insulin (pmol/l) & $58 \pm 46$ & $80 \pm 58$ & 0.035 \\
\hline HOMA-IR value & $2.4 \pm 2.5$ & $3.4 \pm 2.9$ & 0.041 \\
\hline Total adiponectin $(\mu \mathrm{g} / \mathrm{ml})$ & $7.5 \pm 3.5$ & $6.8 \pm 4.0$ & 0.37 \\
\hline HMW adiponectin $(\mu \mathrm{g} / \mathrm{ml})$ & $3.9 \pm 2.3$ & $3.6 \pm 3.1$ & 0.57 \\
\hline FMD & $4.73+2.11$ & $4.38+3.04$ & 0.51 \\
\hline GTN & $15.81 \pm 5.32$ & $17.66 \pm 4.39$ & 0.12 \\
\hline FMD/GTN & $0.32 \pm 0.14$ & $0.24 \pm 0.13$ & 0.018 \\
\hline
\end{tabular}

Values are expressed as mean \pm s.D. BMI, body mass index; MDA-LDL, malondialdehyde-LDL; HOMA-IR, homeostasis model assessment of insulin resistance; HMW, high-molecular-weight; FMD, flow-mediated dilatation; GTN, glyceryl trinitrate-induced dilation. Triglycerides, fasting insulin, and HOMA-IR were logarithmically transformed before statistical analysis.

lower in the carriers of the Asp298 allele than in the non-carriers. Also, BMI and HbAlc had a tendency toward higher levels in the Asp298 carriers. On the other hand, in the $\mathrm{C}-786$ allele carriers, systolic blood pressure was significantly higher $(P=0.04)$ and HMW adiponectin levels were significantly lower $(P=0.03)$ than those in the non-carriers of the $\mathrm{C}-786$ allele.
Plasma fasting insulin, HOMA-IR value, and total adiponectin had a tendency toward higher levels in carriers of the $\mathrm{C}-786$ allele than in non-carriers. When we compared variables in subjects with both alleles $(n=5)$ to those in the others $(n=96)$, there was a significant difference only in FMD/GTN $(0.17 \pm 0.04$ vs $0.31 \pm 0.14, P=0.04)$.

Table 4 Physical and biochemical characteristics of subjects assigned by the presence of the eNOS C-786 allele.

\begin{tabular}{|c|c|c|c|}
\hline eNOS T-786C & $\mathbf{T} / \mathbf{T}(n=81)$ & $\mathrm{T} / \mathrm{C}$ or $\mathrm{C} / \mathrm{C}(n=20)$ & $P$ value \\
\hline Age (years) & $30.3 \pm 4.3$ & $30.3 \pm 3.9$ & 0.99 \\
\hline BMl $\left(\mathrm{kg} / \mathrm{m}^{2}\right)$ & $23.1+2.6$ & $22.4+2.3$ & 0.28 \\
\hline Systolic blood pressure $(\mathrm{mmHg})$ & $119.7 \pm 11.6$ & $126.1 \pm 12.9$ & 0.036 \\
\hline Diastolic blood pressure (mmHg) & $71.2+8.7$ & $73.0+10.0$ & 0.44 \\
\hline Total cholesterol $(\mathrm{mmol} / \mathrm{l})$ & $4.87 \pm 0.77$ & $4.96 \pm 0.78$ & 0.66 \\
\hline $\mathrm{HDL}$ cholesterol (mmol/l) & $1.52 \pm 0.34$ & $1.47 \pm 0.24$ & 0.52 \\
\hline LDL cholesterol (mmol/l) & $2.95+0.68$ & $3.00+0.70$ & 0.80 \\
\hline Triglycerides $(\mathrm{mmol} / \mathrm{l})$ & $1.27 \pm 1.11$ & $1.96 \pm 2.79$ & 0.33 \\
\hline LDL particle size $(\mathrm{nm})$ & $263.4+9.6$ & $260.6+11.1$ & 0.26 \\
\hline MDA-LDL (U/L) & $111.3 \pm 53.1$ & $90.5 \pm 40.2$ & 0.11 \\
\hline Apolipoprotein A-I (mg/dl) & $138.5+20.5$ & $136.1+18.4$ & 0.63 \\
\hline Apolipoprotein B (mg/dl) & $83.2 \pm 18.6$ & $84.4 \pm 20.1$ & 0.81 \\
\hline Fasting glucose $(\mathrm{mmol} / \mathrm{l})$ & $5.41 \pm 0.61$ & $5.13 \pm 0.27$ & 0.050 \\
\hline $\mathrm{HbA1c}(\%)$ & $4.70+0.30$ & $4.67+0.24$ & 0.62 \\
\hline Fasting insulin (pmol/l) & $68.4 \pm 54.6$ & $47.4 \pm 20.4$ & 0.096 \\
\hline HOMA-IR value & $2.9 \pm 2.9$ & $1.8 \pm 0.8$ & 0.067 \\
\hline Total adiponectin $(\mu \mathrm{g} / \mathrm{ml})$ & $7.7 \pm 3.7$ & $6.1 \pm 2.8$ & 0.075 \\
\hline HMW adiponectin $(\mu \mathrm{g} / \mathrm{ml})$ & $4.1+2.5$ & $2.8+1.6$ & 0.026 \\
\hline FMD & $4.81+2.50$ & $3.99+1.54$ & 0.17 \\
\hline GTN & $15.89 \pm 5.27$ & $17.80 \pm 4.40$ & 0.13 \\
\hline FMD/GTN & $0.31 \pm 0.15$ & $0.24 \pm 0.12$ & 0.045 \\
\hline
\end{tabular}

Values are expressed as mean \pm s.D. BMI, body mass index; MDA-LDL, malondialdehyde-LDL; HOMA-IR, homeostasis model assessment of insulin resistance; HMW, high-molecular-weight; FMD, flow-mediated dilatation; GTN, glyceryl trinitrate-induced dilation. Triglycerides, fasting insulin, and HOMA-IR were logarithmically transformed before statistical analysis. 


\section{Discussion}

Extensive epidemiologic evidence has consistently indicated that alterations of endothelial function play a pivotal role in the development of atherosclerosis and predict the occurrence of atherosclerotic complications $(24,25)$. Accumulated evidence strongly suggests that eNOS gene polymorphisms are associated with the bioavailability of eNOS and endothelial function (26-28). However, differences in biochemical phenotypes and clinical findings among the polymorphisms have not yet been fully elucidated. In the present study, to gain insight into the underlying mechanisms by which the presence of the Asp298 or C-786 allele impairs endothelial function, we recruited young, healthy, preclinical subjects, and analyzed how physical and biochemical variables were related to each eNOS gene variant. There are marked differences in the distribution of eNOS polymorphisms among races, and our results are consistent with the previous study (26). Although the two polymorphisms were independent, we found a significantly close relationship between endothelial function and both the Glu298Asp and T-786C polymorphisms, as previously reported $(27,28)$, and suggested that there is a distinct difference in the biological function of the Asp298 and C-786 alleles. Interestingly, the presence of the $\mathrm{C}-786$ allele was significantly closely associated with adiponectin, and particularly HMW adiponectin, while it had little effect on other physical and biochemical variables. Conversely, the Asp298 allele did not affect any adiponectin levels, but adversely altered the atherogenic lipid profile. Namely, the Asp298 allele induced an increase in plasma LDL cholesterol, MDA-LDL, and fasting insulin levels, and decrease in HDL cholesterol and apolipoprotein A-I.

The Asp298 variant, which is an exon 7 polymorphism resulting in an amino acid exchange at position 298 of the eNOS protein of glutamate to aspartate, has been associated with the development of CAD, myocardial infarction, hypertension, and endothelial dysfunction in healthy, young adults (29). Similarly, in terms of the promoter region $\mathrm{T}-786 \mathrm{C}$ polymorphism, a mutation located in the $5^{\prime}$-flanking region of the eNOS gene, the presence of the $\mathrm{C}-786$ allele reduces eNOS protein expression, and therefore has been found to be an independent predictor of coronary spasm (30).

A previous study demonstrated that eNOS with an amino acid substitution at the Asp298 allele was cleaved intracellularly in human endothelial cells and hearts, resulting in the generation of 100 and $35 \mathrm{kDa}$ fragments (31). As a result, eNOS activity in subjects with the Asp298 allele may be decreased, leading to lower endothelium-dependent vascular dilation. However, there have been arguments against intracellular cleavage and, so far, the functional consequences of this polymorphism in a physiological setting have not yet been established (32). On the other hand, in the eNOS $\mathrm{T}-786 \mathrm{C}$ polymorphism, the replication protein $\mathrm{A} 1$, which is known as a DNA-binding protein essential for DNA repair and replication, binds to the $\mathrm{C}-786$ allele and reduces the promotor activity of the eNOS gene, resulting in a decrease of eNOS protein production (33). A luciferase promoter assay indicated that a construct with the $\mathrm{C}-786$ allele decreased the promoter activity by $50 \%(30)$.

To our knowledge, this is the first study to determine the relationship between eNOS gene polymorphisms and plasma adiponectin levels. Adiponectin is an adipocyte-specific secreted protein that is highly expressed in adipose tissue and circulates in plasma at high concentrations. Plasma adiponectin includes three forms: a low-molecular-weight trimer, a mediummolecular-weight hexamer, and a larger HMW multimer. So far, plasma adiponectin levels have been shown to have an inverse relationship with visceral fat accumulation and insulin resistance (34), and the plasma HMW adiponectin level, rather than the absolute amount of adiponectin, has been reported to be the key in determining insulin sensitivity (35).

Plasma HMW adiponectin reduction by the presence of the $\mathrm{C}-786$ allele was significantly accompanied by an increase in systolic blood pressure, and there was a tendency toward lower fasting plasma glucose and HOMA-IR values. Hypoadiponectinemia is reported to predict the development of hypertension in normotensive subjects (36). In the case of $\mathrm{C}-786$ allele carriers in this study, a decrease in plasma adiponectins may precede increased blood pressure and decreased peripheral circulation in adipose tissues. The precise mechanism of decreased adiponectin levels remains to be elucidated although the decreased amount of eNOS protein may be related to plasma adiponectins. In terms of the Asp298 allele, it appears that replacement of one nucleotide alters the eNOS quality rather than the quantity of eNOS production, and as a result, this polymorphism showed no relationship with adiponectin levels. Taken together, the two polymorphisms had similar effects on endothelial function, but the mechanism underlying the impairment of endothelial function in each case may be entirely different.

Few studies have reported a significant relationship between eNOS polymorphisms and serum lipid profiles (37). The reason is that most previous reports have analyzed subjects over 40 years old with overt vascular disease. In the present study, we recruited only young healthy men without apparently overt cardiovascular disease to avoid the environment factors and other genetic factors such as dyslipidemia and hypertension that emerge with aging. Recent data have suggested that Asp variants of the Glu298Asp polymorphism resulted in altered caveolar localization of the eNOS gene and impaired response to shear (38). eNOS activation is associated with an increase in the L-arginine transport protein in the endothelial caveolae (39). In addition, caveolae are very important for lipid metabolism, and are proposed to play a major role in the transcytosis of native 
and modified LDL (40). HDL maintains the concentration of caveolae-associated cholesterol, thereby preventing the negative impact of oxidized LDL. In the presence of the Asp298 allele, the action of the produced eNOS may be different from that of the normally constituted eNOS, and therefore may alter plasma lipid profiles and insulin resistance. In the present study, we encountered only four homozygotes for the Asp298 allele, and their levels of HDL cholesterol and apolipoprotein A-I were significantly lower $(1.09 \pm 0.24 \mathrm{vs} 1.42 \pm 0.24 \mathrm{mmol} / \mathrm{ml}$, $109.0 \pm 18.6$ vs $131.4 \pm 16.1 \mathrm{mg} / \mathrm{dl}$ respectively), while their fasting insulin and HOMA-IR levels were significantly higher ( $141 \pm 72$ vs $69 \pm 49 \mathrm{pmol} / \mathrm{l}, 5.8 \pm 2.7 \mathrm{vs}$ $3.0 \pm 2.8$ respectively) than respective values for heterozygotes, suggesting that the additional effects of the Asp298 allele in homozygotes were due to increased production of the structurally changed eNOS protein. Characteristics of metabolic syndrome as represented by hyperinsulinemia and lowered plasma HDL cholesterol were observed in Asp298 allele carriers. Evidence that Asp298 allele carriers are susceptible to hyperinsulinemia and higher HOMA-IR values has already been reported (14), and eNOS gene polymorphisms including these alleles are associated with features of metabolic syndrome such as insulin resistance, hypertriglyceridemia, and low HDL cholesterol concentrations (16).

Surprisingly, we observed an increase in LDL particle size in Asp298 allele carriers. The variable most closely related to LDL particle size in the present study was plasma triglyceride levels $(r=0.372, P<0.001)$ as previously reported (41). At present, the reason why LDL particle size was elevated in Asp298 allele carriers cannot be explained.

The present study was limited because of the small number of subjects. However, since the two polymorphisms affect endothelial function independently, subjects with both the Asp298 and C-786 alleles must pay more attention to the prevention of atherosclerosis development.

It is concluded that the two polymorphisms of the eNOS gene affect endothelial functions to the same degree, but differently: namely, that the eNOS T-786C polymorphism may determine adiponectin levels in adipose tissue, whereas the Glu298Asp polymorphism may be associated with lipid levels and other metabolic risk factors via both local regulation of blood flow in peripheral tissue and oxidative stress. The phenotypes associated with both polymorphisms are involved in the clinical features of metabolic syndrome, suggesting that the eNOS gene and NO are closely associated with metabolic status.

\section{References}

1 Reaven GM. Role of insulin resistance in human disease. Diabetes 198837 1595-1607.
2 Modan M, Halkin H, Almog S, Lusky A, Eshkol A, Shefi M, Shitrit A \& Fuchs Z. Hyperinsulinemia. A link between hypertension, obesity, and glucose intolerance. Journal of Clinical Investigation 198575 809-817.

3 Matsuzawa Y, Funahashi T, Kihara S \& Shimomura I. Adiponectin and metabolic syndrome. Arteriosclerosis, Thrombosis, and Vascular Biology 200424 29-33.

4 Furukawa S, Fujita T, Shimabukuro M, Iwaki M, Yamada Y, Nakajima Y, Nakayama O, Makishima M, Matsuda M \& Shimomura I. Increased oxidative stress in obesity and its impact on metabolic syndrome. Journal of Clinical Investigation $2004 \mathbf{1 1 4}$ 1752-1761.

5 Hong Y, Pedersen NL, Brismar K \& de Faire U. Genetic and environmental architecture of features of the insulin-resistance syndrome. American Journal of Human Genetics 199760 143-152.

6 Santaniemi M, Kesaniemi YA \& Ukkola O. Low plasma adiponectin concentration is an indicator of the metabolic syndrome. European Journal of Endocrinology 2006155 745-750.

7 Baron AD \& Clark MG. Role of blood flow in the regulation of muscle glucose uptake. Annual Review of Nutrition 199717 487-499.

8 Roy D, Perreault M \& Marette A. Insulin stimulation of glucose uptake in skeletal muscle and adipose tissue in vivo is NO dependent. American Journal of Physiology. Endocrinology and Metabolism 1998274 E692-E699.

9 Phillips SA, Hatoum OA \& Gutterman D. The mechanism of flowinduced dilation in human adipose arterioles involves hydrogen peroxide during CAD. American Journal of Physiology. Heart and Circulatory Physiology 2007292 H93-H100.

10 Duplain H, Burcelin R, Sartori C, Cook S, Egli M, Lepori M, Vollenweider P, Pedrazzini T, Nicod P, Thorens B \& Scherrer U. Insulin resistance, hyperlipidemia, and hypertension in mice lacking endothelial nitric oxide synthase. Circulation $2001 \mathbf{1 0 4}$ 342-345.

11 Cook S, Hugli O, Egli M, Menard B, Thalmann S, Sartori C, Perrin C, Nicod P, Thorens B, Volleweider P \& Scherrer U. Partial gene deletion of endothelial nitric oxide synthase predisposes to exaggerated high-fat diet-induced insulin resistance and arterial hypertension. Diabetes $2004532067-2072$.

12 Ohtoshi K, Yamasaki Y, Gorogawa S, Hayaishi-Okano R, Node K, Matsuhisa M, Kajimoto Y \& Hori M. Association of -786T-C mutation of endothelial nitric oxide synthase gene with insulin resistance. Diabetologia 200245 1594-1601.

13 Tso AWK, Tan KCB, Wat NMS, Janus ED, Lam TH \& Lam KSL. Endothelial nitric oxide synthase G894T (Glu298Asp) polymorphism was predictive of glycemic status in a 5-year prostective study of Chinese subjects with impaired glucose tolerance. Metabolism 200655 1155-1158.

14 Monti LD, Barlassina C, Citterio L, Galluccio E, Berzuini C, Setola E, Valsecchi G, Lucotti P, Pozza G, Bernardinelli L, Casari G \& Piatti P. Endothelial nitric oxide synthase polymorphisms are associated with type 2 diabetes and the insulin resistance syndrome. Diabetes 200352 1270-1275.

15 Antoniades C, Tousoulis D, Vasiliadou C, Pitsavos C, Ghrysochoou C, Panagiotakos D, Tentolouris C, Marinou K, Koumallos N \& Stefanadis C. Genetic polymorphism on endothelial nitric oxide synthase affects endothelial activation and inflammatory response during the acute phase of myocardial infarction. Journal of the American College of Cardiology 200546 1101-1109.

16 Gonzalez-Sanchez JL, Martinez-Larrad MT, Saez ME, Zabena C, Martinez-Calatrava MJ \& Serrano-Rios M. Endothelial nitric oxide synthase haplotypes are associated with features of metabolic syndrome. Clinical Chemistry 200753 91-97.

17 Celermajer DS, Sorenson KE, Gooch VM, Spiegelhalter DJ, Miller OI, Sullivan ID, Lloyd JK \& Deanfield JE. Non-invasive detection of endothelial dysfunction in children and adults at risk of atherosclerosis. Lancet $1992 \mathbf{3 4 0} 1111-1115$.

18 Aso Y, Yamamoto R, Wakabayashi S, Uchida T, Takayanagi K, Takebayashi K, Okuno T, Inoue T, Node K, Tobe T, Inukai T \& Nakano Y. Comparison of serum high-molecular weight (HMW) adiponectin with total adiponectin concentrations in type 2 
diabetic patients with coronary artery disease using a novel enzyme-linked immunosorbent assay to detect HMW adiponectin. Diabetes 200655 1954-1960.

19 Okumura K, Matsui H, Kawakami K, Numaguchi Y, Hayakawa M, Morishima I, Toki Y \& Ito T. Low density lipoprotein particle size is associated with glycosylated hemoglobin levels regardless of plasma lipid levels. Internal Medicine 199837 273-279.

20 Kotani K, Maekawa M, Kanno T, Kondo A, Toda N \& Manabe M. Distribution of immunoreactive malondialdehyde-modified lowdensity lipoprotein in human serum. Biochimica et Biophysica Acta $19941215121-125$.

21 Excoffier L \& Slatkin M. Maximum-likelihood estimation of molecular haplotype frequencies in a diploid population. Molecular Biology and Evolution 199512 921-927.

22 Awata T, Neda T, Iizuka H, Kurihara S, Ohkubo T, Takata N, Osaki M, Watanabe M, Nakashima Y, Sawa T, Inukai K, Inoue I, Shibuya M, Mori K, Yoneya S \& Katayama S. Endothelial nitric oxide synthase gene is associated with diabetic macular edema in type 2 diabetes. Diabetes Care 200427 2184-2190.

23 Anderson TJ, Elstein E, Haber H \& Charbonneau F. Comparative study of ACE-inhibition, angiotensin II antagonism, and calcium channel blockade on flow-mediated vasodilation in patients with coronary disease (BANFF study). Journal of the American College of Cardiology 200035 60-66.

24 Suwaidi JA, Hamasaki S, Higano ST, Nishimura RA, Holmes DR Jr \& Lerman A. Long-term follow-up of patients with mild coronary artery disease and endothelial dysfunction. Circulation 2000101 948-954.

25 Schachinger V, Britten MB \& Zeiher AM. Prognostic impact of coronary vasodilator dysfunction on adverse long-term outcome of coronary heart disease. Circulation 2000101 1899-1906.

26 Tanus-Santos JE, Desai M \& Flockhart DA. Effects of ethnicity on the distribution of clinically relevant endothelial nitric oxide variants. Pharmacogenetics $200111719-725$.

27 Paradossi U, Ciofini E, Clerico A, Botto N, Biagini A \& Colombo MG. Endothelial function and carotid intima-media thickness in young healthy subjects among endothelial nitric oxide synthase Glu298 $\rightarrow$ Asp and T-786 $\rightarrow$ C polymorphisms. Stroke 200435 1305-1309.

28 Rossi GP, Taddei S, Virdis A, Cavallin M, Ghiadoni L, Favilla S, Versari D, Sudano I, Pessina AC \& Salvetti A. The T-786C and Glu298Asp polymorphisms of the endothelial nitric oxide gene affect the forearm blood flow responses of Caucasian hypertensive patients. Journal of the American College of Cardiology 200341 938-945.

29 Hingorani AD, Liang CF, Fatibene J, Lyon A, Monteith S, Parsons A, Haydock S, Hopper RV, Stephens NG, O'Shaughnessy KM \& Brown MJ. A common variant of the endothelial nitric oxide synthase (Glu298Asp) is a major risk factor for coronary artery disease in the UK. Circulation $19991001515-1520$.

30 Yoshimura M, Nakayama M, Shimasaki Y, Ogawa H, Kugiyama K, Nakamura S, Ito T, Mizuno Y, Harada E, Yasue H, Miyamoto Y, Saito Y \& Nakao K. AT-786 $\rightarrow$ C mutation in the $5^{\prime}$-flanking region of the endothelial nitric oxide synthase gene and coronary arterial vasomotility. American Journal of Cardiology 200085 710-714.
31 Tesauro M, Thompson WC, Rogliani P, Qi L, Chaudhary PP \& Moss J. Intracellular processing of endothelial nitric oxide synthase isoforms associated with differences in severity of cardiopulmonary diseases: cleavage of proteins with aspartate vs. glutamate at position 298. PNAS 200097 2832-2835.

32 Fairchild TA, Fulton D, Fontana JT, Gratton JP, McCabe TJ \& Sessa WC. Acidic hydrolysis as a mechanism for the cleavage of the $\mathrm{Glu}(298) \rightarrow$ Asp variant of human endothelial nitric-oxide synthase. Journal of Biological Chemistry 2001276 26674-26679.

33 Abe K, Nakayama M, Yoshimura M, Nakamura S, Ito T, Yamamuro M, Sakamoto T, Miyamoto Y, Yoshimasa Y, Saito Y, Nakao K, Yasue H \& Ogawa H. Increase in the transcriptional activity of the endothelial nitric oxide synthase gene with fluvastatin: a relation with the $-786 \mathrm{~T}>\mathrm{C}$ polymorphism. Pharmacogenetics and Genomics 200515 329-336.

34 Arita Y, Kihara S, Ouchi N, Takahashi M, Maeda K, Miyagawa J, Hotta K, Shimomura I, Nakamura T, Miyaoka K, Kuriyama H, Nishida M, Yamashita S, Okubo K, Matsubara K, Muraguchi M, Ohmoto Y, Funahashi T \& Matsuzawa Y. Paradoxical decrease of an adipose-specific protein, adiponectin, in obesity. Biochemical and Biophysical Research Communications 1999257 79-83.

35 Pajvani UB, Hawkins M, Combs TP, Rajala MW, Doebber T, Berger JP, Wagner JA, Wu M, Knopps A, Xiang AH, Utzschneider KM, Kahn SE, Olefsky JM, Buchanan TA \& Scherer PE. Complex distribution, not absolute amount of adiponectin, correlates with thiazolidinedionemediated improvement in insulin sensitivity. Journal of Biological Chemistry 2004279 12152-12162.

36 Chow WS, Cheung BM, Tso AW, Xu A, Wa NM, Fong CH, Ong LH, Tam S, Tan KC, Janus ED, Lam TH \& Lam KS. Hypoadiponectinemia as a predictor for the development of hypertension: a 5-year prospective study. Hypertension 200749 1455-1461.

37 Lembo G, De Luca N, Battagli C, Iovino G, Aretini A, Musicco M, Frati G, Pompeo F, Vecchione C \& Trimarco B. A common variant of endothelial nitric oxide synthase (Glu298Asp) is an independent risk factor for carotid atherosclerosis. Stroke 200132 735-740.

38 Joshi MS, Mineo C, Shaul PW \& Bauer JA. Biochemical consequences of the NOS3 Glu298Asp variation in human endothelium: altered caveolar localization and impaired response to shear. FASEB Journal $2007212655-2663$.

39 Miner SE, Al-Hesayen A, Kelly S, Benson T, Thiessen JJ, Young VR \& Parker JD. L-arginine transport in the human coronary and peripheral circulation. Circulation 2004109 1278-1283.

40 Frank PG, Woodman SE, Park DS \& Lisanti MP. Caveolin, caveolae, and endothelial cell function. Arteriosclerosis, Thrombosis, and Vascular Biology 200323 1161-1168.

41 Reaven GM, Chen YD, Jeppesen J, Maheux P \& Krauss RM. Insulin resistance and hyperinsulinemia in individuals with small, dense low density lipoprotein particles. Journal of Clinical Investigation 199392 141-146.

Received 24 October 2007

Accepted 7 November 2007 